\title{
Rencana pemeliharaan taman Museum Arma Ubud
}

\author{
Stephany Sinaga ${ }^{1}$, Cokorda Gede Alit Semarajaya ${ }^{1 *}$, Ni Nyoman Ari Mayadewi²
}

1. Prodi Arsitektur Pertamanan, Fakultas Pertanian Universitas Udayana, Indonesia 80232

2. Prodi Agroekoteknologi, Fakultas Pertanian Universitas Udayana, Indonesia 80232

\section{*E-mail: coksemarajaya@unud.ac.id}

\begin{abstract}
Maintenance plan for the Arma Ubud Museum park. Arma Museum is one of the attractions in Bali that displays art the Balinese culture.The Arma Museum also includes the environment or landscapes in the tourism activities through a park covering an area of $1.5 \mathrm{Ha}$, so that the Arma museum needs to maintain and preserve the existing park through well-planned park maintenance. The purpose of this research is to plan an ideal garden maintenance program for the Arma museum park. The research method based on its purpose is research and development research methods. The data needed in the study include several aspects related to the formation of the Arma musuem park, namely; biotic and abiotic aspects, social aspects, economic aspects, as well as aspects of the physical maintenance of the park, and aspects of organizing the maintenance of the park. Data analysis used in this study is an analysis of the application of theory and SWOT analysis. Based on the biotic and abiotic aspects, the social aspects, the economic aspects that have been identified indicate the Arma museum park has a lot of potential that needs to be maximized, maintained, and preserved, but the aspect of physical maintenance of the park and the organizing aspects of the maintenance of Arma Musuem park are still not maximized, the results of the application analysis The theory found a gap between ideal action and actual action in the field, through the identified gaps, the plan for organizing effective park maintenance was organized by reducing existing gaps, while the SWOT Analysis produced seven recommendations for strategic plan.
\end{abstract}

Keywords: environment, ideal maintenance, park maintenance, plan, sustainable park, SWOT analysis

\section{Pendahuluan}

Bali merupakan salah satu daerah tujuan wisata yang terkenal di Indonesia maupun mancanegara. Menurut Pitana (2003) kepariwisataan di Bali menjadi penggerak utama perekonomian dan pembangunan, sehingga kepariwisataan menjadi bagian yang tidak terpisahkan dalam kehidupan masyarakatnya. Bali memiliki banyak hal yang dapat dijadikan sebagai atraksi wisata misalnya upacara adat dan keagamaan, keindahan alam maupun kesenian rakyat.

Museum Arma adalah objek wisata yang menawarkan atraksi kesenian rakyat salah satunya melalui seni lukis yang secara sengaja dimuseumkan sebagai upaya mempromosikan sekaligus melestarikan seni lukis budaya Bali. Museum Arma juga turut mempromosikan dan melestarikan seni tari dan seni musik melalui pendidikan tidak formal kepada anak-anak, remaja dan orang dewasa setempat secara gratis, hal tersebut sekaligus menjadi atraksi wisata kesenian yang dapat dinikmati para wisatawan yang berkunjung ke museum Arma. Selain atraksi kesenian museum Arma menghadirkan keindahan alamnya melalui taman bernuansa tropis Bali pada lanskapnya yang memiliki luas 1,5 Ha. Museum Arma mengikutsertakan lingkungan atau lanskap dalam aktivitas wisatanya untuk menciptakan suasana nyaman bagi pengunjung. Lingkungan hidup museum Arma yang sehat terlihat dari vegetasi yang tumbuh dengan baik sehingga mendukung lanskapnya sebagai citra utama yang ditampilkan kepada pengunjungnya. Menurut Clements (1916), setiap tumbuhan adalah alat pengukur bagi keadaan lingkungan hidup tempat ia tumbuh. Artinya pertumbuhan tanaman yang baik mengindikasikan lingkungan yang baik. Mempertahankan lingkungan yang baik tersebut diperlukan pengelolaan lanskap yang terencana dan berkelanjutan,salah satunya melalui pemeliharaan taman (lanskap skala kecil). Pemeliharaan taman menurut Arifin dan Arifin (2005) dimaksudkan untuk menjaga dan merawat areal taman dengan fasilitas yang ada di dalamnya agar kondisinya tetap baik dan sedapat mungkin mempertahankan keadaan yang sesuai dengan rancangan atau desain semula. Lagi pula lanskap museum Arma tebentuk sejak tahun 1996 sudah seharusnya memiliki 
pemeliharaan untuk mempertahankan dan memaksimalkan potensi lanskap yang ada secara efektif dan berkelanjutan.

\section{Metode}

Tempat pelaksanaan penelitian di Museum Arma Jl. Raya Pengosekan, Mas, Ubud, Kabupaten Gianyar, Bali (Gambar 1). Penelitian dilaksanakan selama 5 bulan, dimulai dari bulan Maret 2018 sampai dengan bulan Juli 2018. Alat yang digunakan pada saat di lapangan dalam penelitian ini adalah alat tulis, voice recorder, handcounter, kamera digital, alat untuk melakukan pengolahan data adalah laptop dengan menggunakan software Adobe Photoshop, Microsoft Excel dan Microsoft Word dan global positioning system (GPS).

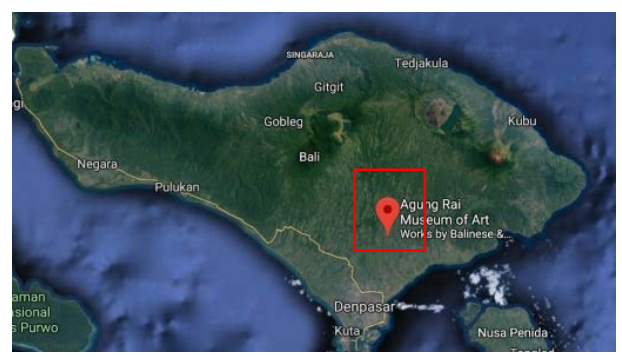

Gambar 1. Lokasi museum Arma

Metode penelitian ini berdasarkan tujuan adalah metode penelitian research and development (R\&D). Teori yang digunakan tidak sepenuhnya diterapkan ataupun tidak sepenuhnya diabaikan tetapi dikembangkan sesuai dengan kondisi yang ditemukan di lapangan (Sugiyono, 2015).

Penelitian menggunakan tiga teknik pengumpulan data yaitu, wawancara, observasi dan kajian literatur. Jenis data yang diperoleh terbagi menjadi dua yaitu data primer dan data sekunder. Data yang dibutuhkan dalam penelitian ini terdiri dari beberapa aspek yaitu aspek biotik dan abiotik, aspek ekonomi, aspek sosial, aspek pemeliharaan fisik taman, aspek pengorganisasian pemeliharaan taman.

Pengolahan data dilakukan dengan menggunkan dua metode analisis yaitu analisis penerapan teori atau tindakan ideal sebagai acuan penyusunan rekomendasi pemeliharaan taman secara efektif dan analisis SWOT untuk menyusun strategi pemeliharaan taman secara berkelanjutan atau disebut rekomendasi jangka panjang.

\subsection{Analisis Penerapan Teori}

Analisis penerapan teori pada penelitian untuk memperlihatkan kesenjangan antara kondisi ideal dengan aktual di lapang terkait dengan aspek pemeliharaan fisik taman dan aspek pengorganisasiannya. Hasil analisis tidak untuk menyimpulkan makna apapun cukup sampai memperlihatkan kesenjangan yang ada. Analisis penerapan teori diharapakan bisa menemukan sesuatu yang berarti dan dikelola sebagai alternatif rekomendasi rencanaan pemeliharaan taman yang efektif sehingga memperkecil kesenjangan antara kondisi ideal dengan kondisi aktual. Analisis penerapan teori berasal dari konsep analisis kesenjangan (gap analysis) oleh Parasuraman et al. (1985), namun sedikit mengalami penyesuaian sehingga analisis yang berlaku disesuaikan dengan tujuan penelitian.

\section{$2.2 \quad$ Analisis SWOT}

Setelah melakukan analisis penerapan teori, selanjutnya dilakukan analisis SWOT untuk menentukan strategi pemeliharaan lanskap taman secara berkelanjutan dan sistematis. Pengumpulan data analisis SWOT dengan merumuskan faktor internal dan eksternal perusahan atau organisasi. Faktor internal diperoleh melalui identifikasi strengths (kekuatan) dan weaknesses (kelemahan), sedangkan faktor eksternal diperoleh melalui identifikasi opportunities (peluang) dan threats (ancaman). Tujuannya untuk dapat memaksimalkan kekuatan dan peluang yang dimilki sekaligus dapat meminimalkan kelemahan dan acaman yang ada. Data diperoleh melalui pengelola kunci perusahaan atau orang yang mengerti perkembangan perusahan. 


\section{Hasil dan Pembahasan}

\subsection{Aspek Biotik dan Abiotik}

\subsubsection{Sejarah Singkat dan Profil Museum Arma}

Museum Arma didirikan oleh pemilikinya Anak Agung Gede Rai. Pada awalnya tahun 1978 merupakan sebuah galeri lukisan dan mulai mengoleksi berbagai jenis lukisan terkenal. Galeri tersebut terus berkembang sampai akhirnya dapat mewujudkan sebuah museum seni budaya Bali yaitu ARMA (Agung Rai Museum of Art). Museum Arma dibuka secara resmi pada tanggal 9 Juni 1996 oleh Prof. Dr. Ing. Wardiman Djojonegoro, Menteri Pendidikan dan Kebudayaan Republik Indonesia. Arma memiliki beberapa bentuk usaha berorientasi profit seperti hotel, resort, kafe dan restoran. Namun museum Arma merupakan perusahan yang bergerak dalam bidang non profit karena dikelola terpisah oleh yayasan Arma yang didirikan pada tanggal 13 Mei 1996. Kegiatan museum Arma didasari dari sebuah visi utama yayasan Arma yaitu menjadikan museum Arma sebagai museum seni dan budaya Bali terkenal secara internasional dengan mempromosikan dan melestarikannya (Official website of museum Arma, 2018).

\subsubsection{Aksesibilitas}

Museum Arma memiliki aksesibilitas yang tinggi karena dilalui jalan utama. Museum Arma mempunyai dua pintu akses masuk yang beralamat di Jalan Raya Pengosekan dan Jalan Made Lebah yang termasuk kedalam kelurahan Mas, kecamatan Ubud, kabupaten Gianyar, Bali.

\subsubsection{Hidrologi}

Hidrologi mencakup sumber air dan saluran drainase pembuangan air. Sumber air yang digunakan untuk pemeliharaan taman berasal dari air tanah yang digali (sumur). Drainase lanskap taman museum Arma dirancang dengan sangat baik sejak awal pembangunan museum Arma dan tidak mengganggu kenyamanan pengunjung. Drainase terbuat dari beton dengan jenis konstruksi semi tertutup. Mealui drainase ini air berlebih disalurkan menuju selokan besar yang berada dijalan raya.

\subsubsection{Tanah}

Kecamatan Ubud termasuk kawasan dengan batuan induk yang berasal dari abu vulkan intermedier, tanah yang terbentuk dari batuan ini adalah jenis tanah regosol coklat kekuningan dan regosol berhumus (Dianasari, 2013). Tanah regosol cenderung gembur dan kaya akan unsur hara serta mempunyai kadar air yang tinggi.

\subsubsection{Iklim}

Berasarkan Badan Meteorologi Klimatologi Geofisika (BMKG) rata- rata unsur iklim dari tahun 20132017, menunjukan wilayah Ubud memiliki suhu udara sekitar $25,7-29,7^{\circ} \mathrm{C}$ dengan rata-rata suhu mencapai $27,7^{\circ} \mathrm{C}$. Kecepatan angin wilayah Ubud rata-rata adalah $6,3 \mathrm{Knot}$ yang dominan kearah barat, sedangkan kelembapan udara memiliki nilai 78,2\%. Rata-rata curah hujan 194,95 mm/bulan, sedangkan nilai rata- rata lama penyinaran matahari adalah 64,4\%.

\subsubsection{Vegetasi dan Satwa}

Taman Museum Arma memiliki banyak keanekaragaman vegetasi dan satwa. Vegetasi yang ada meliputi tanaman pohon, semak atau perdu, tanaman rambat dan groundcover. Jenis tanaman yang mendominasi taman adalah sebagi berikut: Pohon (tingginya lebih dari $6 \mathrm{~m}$ ): maja (Aegle marmelos), asam jawa (Tamarindus indica L), jepun (Plumeria Sp), dan bambu kuning (Phyllostachys sulphrurea). Perdu (tingginya dibawah $6 \mathrm{~m}$ ): andong (Cordyline $s p$ ), bungenvil (Bougainvillea), melati jepang (Pseuderanthemum reticulatum). Semak (tingginya antara 0,5 - $3 \mathrm{~m}$ ): iris kuning (Neomarica longifolia), pisang hias (Heliconia sp), palem wregu (Rhapis excels). Tanaman rambat: trumpet vine (Thunbergia sp). Penutup tanah (tingginya kurang dari atau sama dengan 0,5 m): jaburan hijau (Ophiopogon jaburan). rumput jepang (Zoysia japonica) dan rumput gajah mini ( Pennisetum purpureum cv. Mott),

Jenis satwa juga beraneka ragam karena lingkungan museum Arma dapat dikategorikan masih asri dan sehat. Beberapa satwa lain yang terlihat pada saat pengamatan seperti ular, ikan, kupu-kupu, kadal dan burung liar yang hinggap kicauannya selalu terdengar di areal taman.

\subsubsection{Visual Lanskap}

Museum Arma memiliki lanskap yang luas dan tema lanskapnya seperti jungle tropis Bali. Pepohonan yang rindang, semak dan perdu yang semarak ditambah gemericik air dari kolam memberikan 
suasana sejuk dan tenang. Banyak pengunjung yang terkesan dengan jenis tanaman, ornamen taman dan suasana sejuk dan tenang pada lanskap taman museum Arma.

\subsubsection{Fasilitas}

Museum Arma memiliki sarana yang mendukung aktivitas pengunjung antara lain kafe, warung kopi, bangku, stage, gazebo, tempat parkir , tempat sampah, signage dan toilet. Fasilitas-fasilitas tersebut berada dalam area museum Arma.

\subsection{Aspek Ekonomi}

Tarif tiket masuk museum Arma ditawarkan sebesar Rp. 80.000/orang sudah dapat menikmati koleksi museum Arma dan menikmati suasana lanskap tanpa batas atau sampai batas museum Arma tutup. Namun apabila pengunjung meminta permintaan khusus seperti pertunjukan teater, kelas tari dan musik akan dikenakan biaya tambahan sesuai permintaan. Museum Arma juga sering dijadikan tempat penyelengaraan event seperti pementasan dan workshop kesenian. Selain kegiatan tersebut museum Arma juga menyediakan paket pelayanan untuk para seniman yang ingin melelang lukisannya, setiap lukisan yang terjual museum Arma akan mendapatkan beberapa persen dari harga lukisan (persentase tergantung kesepakatan). Kondisi lanskap sangat mendukung setiap kegiatan yang bisa menambah perekonomian museum Arma. Kontribusi museum Arma terhadap ekonomi masyarakat setempat adalah melalui karyawan museum Arma yang sebagian besar memperkerjakan masyarakat lokal dari jabatan terendah sampai yang tertiggi.

\subsection{Aspek Sosial}

Museum Arma mulai buka dari pukul 09.00 sampai dengan 18.00. Aktivitas yang dapat dilakukan setiap harinya adalah menikmati koleksi lukisan museum Arma, melihat langsung proses pembuatan lukisan karya seniman lokal, menikmati suasana lanskap area museum Arma, menikmati proses latihan seni tari dan musik budaya Bali oleh masyarakat setempat. Selain itu pengunjung juga dapat menikmati pameran lukisan dari seniman dalam negeri maupun luar negeri tetapi kegiatan ini dilakukan hanya pada waktu tertentu.

Pengunjung museum Arma datang dari berbagai negara, jumlah pengunjung museum Arma mencapai 1.529 sampai 3.119 orang setiap bulannya. Pengunjung tertinggi terdapat pada bulan Juli sampai September.

Berdasarkan kuesioner yang telah disebar kepada 30 orang pengunjung musuem Arma dari berbagai negara, menghasilkan persepsi terhadap beberapa indikator penilaian seperti kebersihan taman, keindahan taman, fungsional taman, kesehatan lingkungan, keamanan lingkungan (indikator standar pemeliharaan taman menurut Arifin dan Arifin, 2005). Penilain menggunakan skala Linkert (Kinnear dan Taylor, 1991) yaitu sangat baik, baik, cukup baik dan tidak baik. Sebanyak 60\% mengatakan kebersihan taman sangat baik, 67\% mengatakan keindahan taman sangat baik, 60\% mengatakan fungsional taman sangat baik, 67\% mengatakan kesehatan lingkungan sangat baik dan $67 \%$ mengatakan keamanan lingkungan sangat baik.

Secara keseluruhan penilain pengunjung terhadap indikator (kebersihan taman, keindahan taman, fungsional taman, kesehatan lingkungan, keamanan lingkungan) rata-rata sudah baik, khususnya terhadap indikator kesehatan lingkungan yang tidak ada mendapat penilai cukup ataupun buruk. Hal tersebut cukup membuktikan ekologi lanskap museum Arma masih baik.

\subsection{Aspek Pemeliharaan Taman museum Arma}

\subsubsection{Pemeliharaan Ideal}

Pemeliharaan taman museum Arma secara ideal dilaksanakan mengikuti tujuan desain awal, namun tidak pernah diadakan suatu evaluasi berkala untuk menyesuaikan keadaan sesunguhnya dengan desain semula (gambar 2). 


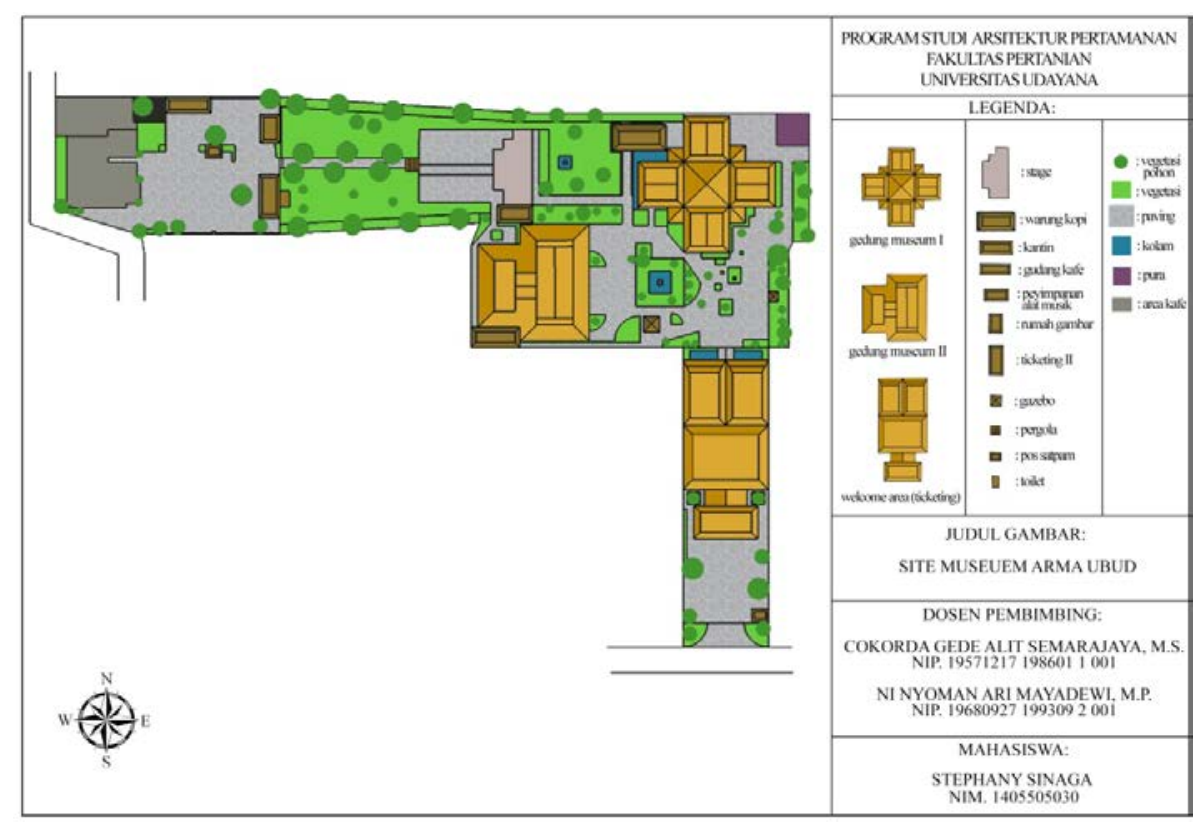

Gambar 2. Site museum Arma

\subsubsection{Pemeliharaan Fisik}

Secara umum pemeliharaan fisik taman museum Arma dapat dikategorikan cukup sederhana, hal tersebut menjadikan kegiatan pemeliharaan taman dipercayakan sepenuhnya kepada gardener dan tanpa terlihat adanya pengawasan secara khusus. kegiatan pemeliharaan fisik yang dilakukan museum Arma untuk soft material adalah pemangkasan rumput (sekali dalam dua minggu) dan dahan pohon (insidentil), penyiraman tanaman (setiap hari), pemupukan (sekali dalam satu tahun), pembersihan areal taman (setiap hari). sedangkan untuk kegiatan pemeliharaan fisik hard material adalah pembersihan kolam (insidentil) dan pembersihan gedung museum (setiap hari).

\subsection{Aspek Pengorganisasian Pemeliharaan Taman Museum Arma}

Pemeliharaan taman atau lanskap museum Arma adalah tanggung jawab departemen General Affairs. General Affairs memiliki divisi yang sangat kompleks, departemen ini mengelola bagian umum dari perusahaan seperti; divisi Human Resource Development (HRD), divisi Engineering, divisi Gardening, divisi Driver, divisi Security. Kelima divisi dalam pengawasan satu manajer yaitu manajer General Affair. Struktur organisasi taman belum ada dalam bentuk tertulis.

Museum Arma saat ini memiliki tujuh gardener, setiap gardener bertanggung jawab terhadap wilayah yang sudah diberikan. Gardener dituntut untuk inisiatif terhadap lingkungan yang menjadi tanggung jawabnya masing-masing tanpa harus diperintah atau diberitahu.

Semua gardener bekerja pada shift pagi dari pukul 07.00 hingga pukul 15.00. Gardener bekerja enam hari dan libur satu hari dalam seminggu, hari libur dimusyawahkan oleh sesama gardener saja.

Alat dan bahan pemeliharaan taman museum Arma disesuaikan dengan kegiatannya yang masih sederhana seperti peralatan menyapu, selang untuk menyiram tanaman dan mesin pemotong rumput. Tempat penyimpanan alat dan bahan belum ada secara khusus. Penyediana barang dapat diajukan oleh gardener langsung kepada department Accounting, jika barang yang dibutuhkan tergolong besar atau mahal disampaikan terlebih dahulu kepada manajer pengelolaan taman museum Arma.

Anggaran pemeliharan taman belum pernah tersusun. Namun untuk gaji gardener dapat diketahui melalui wawancara kepada setiap gardener. Pengelola museum Arma mengeluarkan biaya sebesar \pm Rp.11.820.000 per bulan untuk tujuh orang gardener dengan jumlah gaji yang berbeda untuk setiap orang. 


\subsection{Analisis dan Sintesis}

\subsubsection{Analisis Penerapan Teori}

Aspek Pemeliharaan Fisik Taman

Analisis aspek pemeliharaan taman dibagi menjadi dua yaitu pemeliharaan soft material dan pemeliharaan hard material. Variabel analisis yang dibandingkan pada pemeliharaan soft matrial sebanyak 8 variabel yaitu pemangkasan, penyiraman, pemupukan, penggemburan tanah, penyiangan gulma, pengendalian hama dan penyakit, penyulaman tanaman, pembiakan tanaman baru. Sedangkan variabel analisis pemeliharaan hard material yang dibandingkan sebanyak 3 variabel yaitu kolam tanam, bangunan fasilitas pelayanan dan perkerasan. Variabel dipilih berdasarkan kegiatan yang sudah dilakukan perusahaan dan kegiatan yang belum dilakukan tetapi sudah seharusnya dilakukan untuk mencapai pemeliharaan yang ideal. Hasil analisis penerapan teori berdasarkan rumus perhitungan efektivitas penerapan teori menujukan aspek pemeliharaan fisik untuk soft material sebesar 37,5\% dan untuk hard material sebesar $44,4 \%$. Efektivitas penerapan teori aspek pemeliharaan fisik museum Arma dikategorikan cukup rendah, namun bukan berarti kondisi lanskap museum Arma dikategorikan rendah juga atau buruk. Tanaman (soft material) adalah elemen lanskap dominan museum Arma, pertumbuhan tanamannya tidak mengalami gangguan atau kerusakan yang signifikan meski pemeliharaan yang dilakukan belum ideal atau belum berdasarkan teori, hal ini dapat terjadi akibat beberapa faktor pendukung salah satunya lingkungan hidup yang masih baik karena pembangunan maupun keberadaan museum Arma tidak banyak mengubah bentuk ekologi aslinya.

\section{Aspek Pengorganisasian Pemeliharaan Taman}

Aspek perencanaan pemeliharaan taman memiliki 5 variabel analisis perbandingan yaitu, struktur organisasi, tenaga kerja, jadwal kerja, peralatan pemeliharaan taman, rencana anggaran biaya. Nilai efektif yang diperoleh untuk rencana pengorganisasian taman museum Arma adalah yang paling rendah yaitu sebesar $13,3 \%$. Variabel yang diberi nilai 0 (nol) adalah struktur organisasi, jadwal kerja dan rencana anggaran biaya. Struktur organisasi pemeliharaan taman belum spesifik dan masih belum jelas secara tertulis maupun dalam pelaksanaan, sehingga data administrasi pemeliharaan taman belum ada sejak lanskap museum Arma berdiri. Pengorganisasian pemeliharaan taman yang baik belum diterapkan sepenuhnya karena belum adanya kesadaran pentingnya aspek tersebut, ditambah belum adanya tenaga ahli dalam merencanakan pemeliharaan taman yang efektif.

\subsubsection{Rekomendasi Rencana Pemeiharaan Taman Museum Arma Struktur organisasi}

Pemeliharaan taman pada umumnya bagian dari divisi arsitektur pertamanan yang terdiri dari beberapa seksi yang bekerja secara spesifik dengan tujuan untuk mencapai efisiensi dan efektivitas kerja (Arifin dan Arifin, 2005). Lahan museum Arma dengan luasan $\pm 1,5 \mathrm{Ha}$, membutuhkan supervisor sekaligus administrator. Pada umumnya supervisor dilakukan secara terpisah oleh orang yang berbeda namun dalam pemeliharaan taman museum Arma dapat dilakukan oleh satu orang saja.

\section{Manager Devisi Pemeliharaan Taman}

Supervisor (Administrator)

Gardener

Gambar 3. Rekomendasi bagan struktur organisasi divisi pemeliharaan taman museum Arma

Deskripsi pekerjaan lebih banyak membebankan kepada supervisor karena memang ditujukan untuk membantu manajer dalam pemeliharaan taman sehingga manajer hanya bertanggung jawab terhadap permasalah umum. Sedangkan untuk permasalahan yang lebih spesifik dipercayakan kepada supervisor sekaligus administrator. Berikut ini rekomendasi rancangan deskripsi pekerjaan manajer dan supervisor pemeliharaan taman museum Arma; Deskripsi pekerjaan manajer divisi pemeliharaan taman; (1) menetapkan sasaran atau tujuan pemeliharaan; (2) membuat struktur koordinasi dan tanggung jawab; (3) memberi motivasi dan berkomunikasi; (4) evaluasi kegiatan secara berkala. Deskripsi pekerjaan supervisor (administrasi): (1) membuat monitoring card untuk setiap gardener; (2) memastikan ketersediaan alat dan 
bahan sesuai kebutuhan; (3) memberi motivasi kerja kepada gardener; (4) melaksanakan breafing gardener; (5) mengetahui dan membuat kapasitas kerja pemeliharaan; (6) menyusun frekuensi kegiatan pemeliharaan; (7) membuat jadwal pemeliharaan jangka panjang maupun jangka pendek; (8) membuat masa efektif peralatan pemeliharaan; (9) perancangan anggaran biaya pemeliharaan; (10) koordinasi dengan divisi engineering terkait pemeliharaan lanskap; (11) mengontrol dan memberikan evaluasi terhadap kinerja bawahannya; (12) menegakkan aturan yang telah dibuat oleh perusahaan agar tercipta kedisiplinan kerja; (13) bertanggung jawab atas hasil kerja gardener; (14) berkomunikasi dengan manajer dan memberi laporan pertanggung jawaban.

\section{Ketenagakerjaan Pemeliharaan}

Berdasarkan perhitungan Harian Orang Kerja (HOK) museum Arma membutuhkan tenaga kerja pemeliharaan taman sebanyak delapan orang. Saat ini museum Arma memilki tujuh orang gardener. Dalam mengoptimalkan kinerja dibutuhkan penambahan satu orang gardener.

\section{Jadwal Pemeliharaan}

Jadwal perlu direncanakan secara sistematis untuk mencapai pemeliharan yang efektif (Arifin dan Arifin, 2005). Supervisor harus setiap hari membuat monitoring card sesuai kebutuhan pemeliharaan taman dan jadwal pemeliharaan. Melalui monitoring card supervisor tidak harus terus menerus mengawasi setiap pekerjaan gardener sehingga dapat melaksanakan pekerjaan yang lain seperti penyusunan administrasi atau memonitor pekerjaan insidental. Monitoring card disusun berdasarkan frekuensi pemeliharaan dalam satu tahun yang telah disusun sebelumnya. Rekomendasi rencana frekuensi pemeliharan taman museum Arma disajikan pada Tabel 1.

Tabel 1. Rekomendasi frekuensi pemeliharaan museum Arna

\begin{tabular}{clc}
\hline No & \multicolumn{1}{c}{ Kegiatan Pemeliharaan } & Frekuensi \\
\hline 1 & Pembersihan areal taman & Setiap hari \\
2 & Pembersihan bangunan taman & Setiap hari \\
3 & Penyiraman tanaman & Setiap hari \\
4 & Pemangksan rumput & 2 minggu sekali \\
5 & Penggemburan tanah & 1 bulan sekali \\
6 & Perbanyakan tanaman & 1 bulan sekali \\
7 & Pembersihan kolam taman & 3 bulan sekali \\
8 & Pemupukan & \\
& $-\quad$ semak dan pohon (pupuk kandang) & 6 bulan sekali \\
& - rumput (Urea [N]) & 6 bulan sekali \\
9 & Pembersihan lumut pada perkerasan & 1 tahun sekali \\
10 & Pemangkasan ranting dan dahan pohon & 1 tahun sekali \\
11 & Pengecatan ulang elemen taman & insidentil \\
12 & Penyulaman / penjarangan & insidentil \\
13 & Pembersihan gulma & insidentil \\
14 & Perbaikan & insidentil \\
\hline
\end{tabular}

Alat dan Bahan Pemeliharaan Taman

Ketersediaan alat dan bahan pemeliharaan yang memadai sangat menentukan keberhasilan pemeliharaan taman. Menurut Arifin dan Arifin (2005) efektivitas kerja sangat ditentukan oleh beberapa hal salah satunya adalah ketersedian alat dan bahan. Secara umum peralatan dan bahan pemeliharaan yang dibutuhkan taman museum Arma masih sangat sederhana. Berikut rekomedasi alat dan bahan serta jumlah yang dibutuhkan berdasarkan kegiatannya; Pembersihan areal rumput dan perkerasan: sapu rake (2), sapu lidi (5); tempat sampah dorong (5); kerajang tempat sampah 8) Pembersihan bangunan tanaman: pel panjang (3); Penyiraman tanaman: selang pelastik 10 meter (6); Pemangksan ranting/ pohon: gunting taman (8), arit (8), batu pengasah (3); Penggemburan tanah dan penyiangan: sekop penggembur (8), garpu penggembur (8); Perbanyakan tanaman: gunting tanaman (8); Pembersihan kolam: tongkat sikat lantai (3), sikat lantai gagang (3); Pemupukan: sekop panjang (2), grobak pasir (2); Pengecatan ulang elemen taman: kuas cat bulu dan roll (3); Keamanan gardener: seragam gardener (8), jas hujan (8), sepatu boot (8), sarung tangan (8). Topi (8); masker mulut; Kebutuhan bahan untuk pemeliharaan taman persatu kegiatan sebagai 
berikut; pupuk kompos $(13607,8 \mathrm{Kg})$, pupuk urea $(2 \mathrm{Kg})$, Bensin (1,2 Liter), pelumas besi (1 botol) dan polybag untuk perbanyakan tanaman $(1 \mathrm{Kg})$.

Alat dan bahan disimpan dengan baik pada satu tempat, oleh karenanaya museum Arma harus memiliki gudang khusus penyimpanan peralatan dan bahan untuk mempermudah pendataan barang dan menjaga peralatan lebih tahan lama. Selanjutnya peralataan pemeliharaan harus diketahui masa efektifnya untuk megetahui biaya penyusutan barang dalam rencana anggaran pemeliharaan taman. Masa efektif barang dapat diketahui melalui pengalaman atau studi pustaka pemeliharaan taman.

Kebutuhan Biaya Pemeliharaan

Rekomendasi upah tenaga untuk satu orang gardener per bulan adalah sebesar Rp. 2.584.919,26. Jumlah tersebut ditentukan berdasakan Hari Orang Kerja (HOK) dan sudah disesuaikan dengan Upah Minimum Kota Gianyar (UMK) 2018. Setelah biaya upah tenaga kerja dirincikan, selanjutnya kebutuhan anggaran biaya penyusutan alat dan bahan pemeliharaan taman museum Arma. Total kebutuhan anggaran biaya penyusutan alat sebesar Rp. 13.853 .000 per tahun, sedangkan total kebutuhan anggaran bahan habis pakai sebesar Rp. 68.286 .960 per sekali kegiatan.

3.6.3 Analisis SWOT

Analisis SWOT yang telah diberi rating dan bobot menghasilkan skor 2,255 untuk Internal Factor Evaluation (IFE) dan 2,486 untuk External Factor Evaluation (EFE). Matriks (IFE) dan matriks EFE dapat dilihat pada Tabel 2 berikut ini.

Tabel 2. Matriks Internal Factor Evaluation (IFE) dan External Factor Evaluation (IFE)

\begin{tabular}{|c|c|c|c|c|}
\hline Simbol & Faktor Internal & Rating & Bobot (B) & $\begin{array}{l}\text { Skor } \\
(\mathrm{R} \times \mathrm{B})\end{array}$ \\
\hline \multicolumn{5}{|c|}{ Kekuatan } \\
\hline S1 & Lahan terbuka (outdoor) lebih luas daripada lahan tetutup (indoor) & 4 & 0,064 & 0,255 \\
\hline S2 & $\begin{array}{l}\text { Penataan taman mengandung nilai-nilai budaya Bali yang } \\
\text { mengesankan pengunjung }\end{array}$ & 4 & 0,064 & 0,255 \\
\hline S3 & $\begin{array}{l}\text { Sebagian besar menggunakan tanaman lokal yang dapat } \\
\text { dimanfaatkan untuk upakara. }\end{array}$ & 4 & 0,064 & 0,255 \\
\hline S4 & Kebersihan taman adalah prioritas utama & 2 & 0,152 & 0,304 \\
\hline S5 & Drainase lanskap terencana & 2 & 0,152 & 0,304 \\
\hline \multicolumn{5}{|c|}{ Kelemahan } \\
\hline W1 & $\begin{array}{l}\text { Pihak perusahan belum memiliki tenaga kerja ahli yang mengerti } \\
\text { tentang pemeliharaan lanskap }\end{array}$ & 1 & 0,064 & 0,064 \\
\hline W2 & Belum memiliki tujuan standar pemeliharaan taman & 2 & 0,127 & 0,255 \\
\hline W3 & Pengorganisasian pemeliharaan taman belum terencana baik & 1 & 0,064 & 0,064 \\
\hline W4 & $\begin{array}{l}\text { Pengelola museum Arma belum melakukan pengolahan sampah } \\
\text { secara mandiri }\end{array}$ & 2 & 0,127 & 0,255 \\
\hline W5 & Pengelola museum Arma belum memilki pembibitan tanaman sendiri & 2 & 0,123 & 0,245 \\
\hline \multicolumn{2}{|c|}{ Total IFE } & & 1 & 2,255 \\
\hline
\end{tabular}


Lanjutan Tabel 2. Matriks Internal Factor Evaluation (IFE) dan External Factor Evaluation (IFE)

\begin{tabular}{llccc}
\hline Simbol & \multicolumn{1}{c}{ Faktor Internal } & Rating & Bobot (B) & $\begin{array}{c}\text { Skor } \\
(\mathrm{R} \times \mathrm{B})\end{array}$ \\
\hline Peluang & Lanskap museum Arma sebagai tempat pengadaan event & 4 & 0,086 & 0,343 \\
O1 & $\begin{array}{l}\text { Lang dapat menambah pemasukan keuangan } \\
\text { O2 }\end{array} \quad \begin{array}{l}\text { Museum Arma memiliki Aksesibilitas yang tinggi } \\
\text { O3 }\end{array} \quad \begin{array}{l}\text { Lanskap museum Arma dapat menjadi sarana edukasi dan } \\
\text { pelestarian budaya Bali }\end{array}$ & 3 & 0,200 & 0,600 \\
Ancaman & 3 & 0,200 & 0,600 \\
T1 $\quad$ Biaya pemeliharaan semakin mahal & 1 & 0,086 & 0,086 \\
T2 $\quad$ Seni budaya Bali tergerus dalam globalisasi & 2 & 0,200 & 0,400 \\
T3 $\quad \begin{array}{l}\text { Lahan terbuka sekitar museum Arma semakin berkurang } \\
\text { akibat peningkatan pembangunan }\end{array}$ & 2 & 0,229 & 0,457 \\
\hline Total EFE & & 1 & 2,486 \\
\hline
\end{tabular}

Berdasarkan hasil skor diketahui posisi kondisi taman museum Arma saat ini. Gambar 5 meperlihatkan posisi taman museum Arma berada pada posisi sel V. Menurut David (2010) posisi pada kuadran $\mathrm{V}$ menunjukan strategi yang paling tepat digunakan adalah dengan menjaga dan mempertahankan (hold and maintain). Dengan kondisi hold and maintain diharapakan museum Arma dapat mempertahankan kondisi tamannya dengan melakukan pemeliharaan secara berkelanjutan.

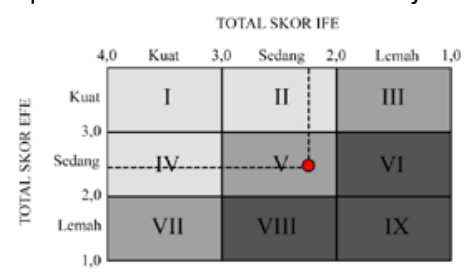

Gambar 5. Matriks Internal - Eksternal (IE)

\subsubsection{Rekomendasi Strategi Pengelolaan Taman Musuem Arma}

Analisis SWOT yang telah dilakukan menghasilkan rekomendasi strategi yang dapat digunakan untuk pemeliharaan taman museum Arma jangka panjang. Strategi yang dihasilkan disusun kembali berdasarkan prioritas yang ditentukan melalui skor setiap faktor terkait. Skor yang tertinggi dindikasikan strategi yang lebih prioritas. Penyusunan rekomendasi strategi berdasarkan tingkat prioritas disajikan pada Tabel 3.

Tabel 3. Susunan strategi hasil analsisi SWOT berdasarkan prioritas

\begin{tabular}{|c|c|c|c|}
\hline Strategi & Unsur SWOT & Skor & Peringkat \\
\hline $\begin{array}{l}\text { 1. Memaksimalkan fungsi lanskap sebagai tempat pengadaan } \\
\text { event yang strategis dengan memanfaatkan dan } \\
\text { mempertahankan keunggulan lanskap }\end{array}$ & $\begin{array}{l}\mathrm{O} 1, \mathrm{O} 2 \\
\mathrm{~S} 1, \mathrm{~S} 2, \mathrm{~S} 4 \\
\mathrm{~S} 5\end{array}$ & 2,06 & 1 \\
\hline $\begin{array}{l}\text { 2. Menjadikan lanskap sebagai sarana edukasi dan pelestarian } \\
\text { budaya Bali melalui pengenalan tanaman. }\end{array}$ & O3, S2, S3 & 1,11 & 3 \\
\hline $\begin{array}{l}\text { 3. Penggunaan tanaman lokal tidak memerlukan pemeliharaan } \\
\text { yang intensif sehingga dapat mengurangi biaya pemeliharaan. }\end{array}$ & $\mathrm{S} 3, \mathrm{~T} 1$ & 0,34 & 7 \\
\hline $\begin{array}{l}\text { 4. Penerapan penuh budaya Bali dalam elemen taman untuk } \\
\text { meperkecil tergerusnya budaya Bali. }\end{array}$ & S2, T2 & 0,65 & 5 \\
\hline $\begin{array}{l}\text { 5. Lahan terbuka yang sudah ada dipetahanakan agar tidak } \\
\text { dibangun }\end{array}$ & $\mathrm{S} 1, \mathrm{~T} 3$ & 0,71 & 4 \\
\hline $\begin{array}{l}\text { 6. Mengelola potensi lanskap museum Arma dengan } \\
\text { menggunakan tenaga ahli dan pemeliharaan lanskap yang } \\
\text { terencana }\end{array}$ & $\begin{array}{l}\text { O1, O2, O3, } \\
\text { W1, W2, W3 }\end{array}$ & 1,93 & 2 \\
\hline $\begin{array}{l}\text { Menekan biaya pemeliharaan dengan membuat pembibitan } \\
\text { tanaman dan pengolahan sampah secara mandiri }\end{array}$ & T1, W4, W5 & 0,59 & 6 \\
\hline
\end{tabular}




\section{Simpulan dan Saran \\ 4.1 Simpulan}

Berdasarkan hasil identifikasi lanskap dari aspek biotik dan abiotik, aspek ekonomi dan aspek sosial, museum Arma memiliki potensi yang cukup banyak. Namun dari aspek pemeliharan fisik taman dan aspek pengorganisasian pemeliharaan taman masih belum terencana secara ideal. Guna memaksimalkan potensi yang berkelanjutan secara efektif museum Arma memerlukan rencana pemeliharaan yang ideal. Analisis penerapan teori membuktikan aspek pemeliharaan fisik taman dan pengorganisasian pemeliharaan taman musuem Arma kurang terencana secara ideal. Analisis penerapan teori memperlihatkan kesenjangan tindakan aktual di lapangan dengan tindakan ideal, penerapan teori untuk pemeliharaan taman soft material mencapai 37,5\% dan untuk hard material 44,4\%, kesenjangan tertinggi ada pada aspek pengorganisasian pemeliharaan taman karena penerapan teorinya hanya mencapai 13,3\%. Aspek pengorganisasian pemeliharaan taman mempengaruhi aspek pemeliharaan fisik taman. Oleh karena itu, rekomendasi rencana pengorganisasian pemeliharaan taman yang telah disusun perlu diterapkan untuk memperkecil kesenjangan antara tindakan aktual dan tindakan ideal yang seharusnya dilakukan, sehingga kinerja pengelola menjadi efektif. Sedangkan analisis SWOT menunjukkan pengelola museum Arma perlu melakukan strategi hold and maintain (menjaga dan mempertahankan lanskapnya) melalui tujuh rencana strategi pemeliharaan taman yang berkelanjutan.

\subsection{Saran} sebagai berikut:

Saran yang dapat diberikan untuk pengelola taman museum Arma dan peneliti selanjutnya adalah

1. Pemimpin museum Arma sebaiknya membentuk sebuah sistem pemeliharaan lanskap taman secara khusus karena banyak sekali potensi yang bisa dikembangkan dari lanskap taman museum Arma.

2. Pengelola juga harus memilki keahlian dalam mengelola lanskap taman sehingga sesuai dengan prinsip-prinsip pengelolan lanskap taman yang berkelanjutan.

3. Penelitian lebih lanjut diperlukan untuk membuktikan kondisi ekologi museum Arma lebih mendalam dengan mengidentifikasi perubahan yang sudah terjadi pada lanskapnya.

\section{Daftar Pustaka}

Arifin, H. S dan N. H. S. Arifin. (2005). Pemeliharaan Taman Cetakan VIII Edisi Revisi. Penebar Swadaya. Jakarta.

Clements, F.E. (1916). Plant Sucession: An Analysis of the development of vegetation. Carnegie Inst. Wash. Pub.

David, F. R. (2010). Manajemen Strategi. Salemba Empat Terjemahan dari: Management: Concept and Cases. Jakarta

Dianasari, D. A. M. L. (2013). Implementasi Tri Hita Karana Dalam Pariwisata Di Bali (Studi Kasus HotelHotel di Ubud, Gianyar). Laporan Penelitian Sekolah Tinggi Pariwisata Nusa Dua Bali. Jurnal of Studylibid, Volume 1.5.188.

Kinnear, T. C and J. R. Taylor. (1991). Marketing Research: An Applied Approach. New York (US): Mcgraw Hill Inc.

Official Website of Museum Arma. (2018). Arma Museum and Resort. Available online at: www.armabali.com (accessed 5 Juni 2018).

Parasuraman, A., Zeithaml VA., Berry LL. (1985). A Conceptual Model of Service Quality and Its Implications for Future Research. Journal of Marketing, Fall. 49: 41-44.

Pitana, I. G. (2003). Reinvention of Bali: Menata Bali Pasca Tragedi Menuju Pariwisata Berkualitas dan

Berkelanjutan. Universitas Udayana. Denpasar.

Sugiyono. (2015). Metode Penelitian Pengelolaan. C.V. Alfabeta. Bandung. 